Supporting Information

\title{
Strategies for Perfect Confinement of POM@MOF and Its Applications in Producing Defect-Rich Electrocatalyst
}

Xingyu Luo ${ }^{\mathrm{a}}$, Fengjiao Li ${ }^{\mathrm{a}}$, Fei Peng ${ }^{\mathrm{a}}$, Lizhen Huang ${ }^{\mathrm{a}}$, Xiaoling Lang ${ }^{\mathrm{b}}$, Meiqin Shi* ${ }^{\mathrm{a} *}$

a: State Key Laboratory Breeding Base of Green Chemistry-Synthesis Technology,

College of Chemical Engineering, Zhejiang University of Technology

Hangzhou 310032, Zhejiang, China

*Corresponding author. Email: smq@zjut.edu.cn

b: Fujian Provincial Key Laboratory of Clean Energy Materials

Longyan 364000, Fujian, China 


\section{Section I}

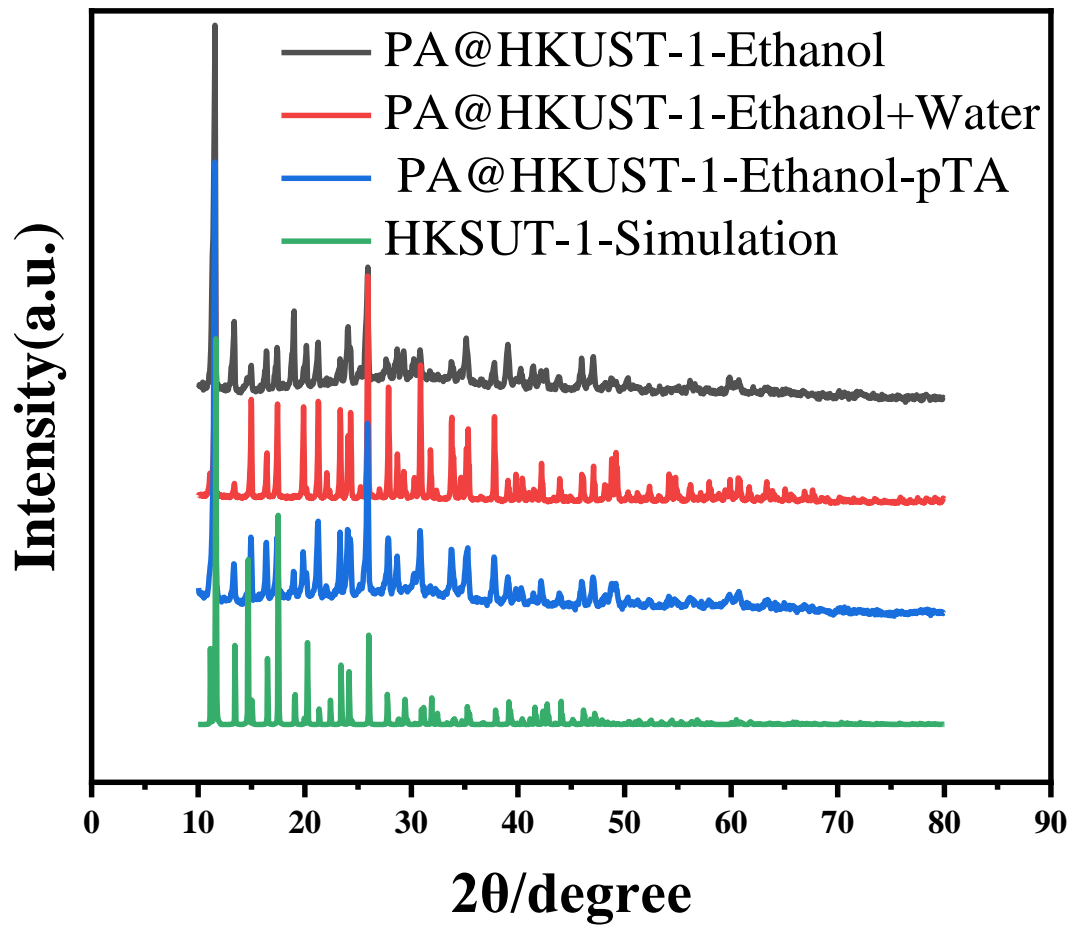

Figure S1. XRD patterns of PA@HKUST-1 precursor with different synthesis pathway. 


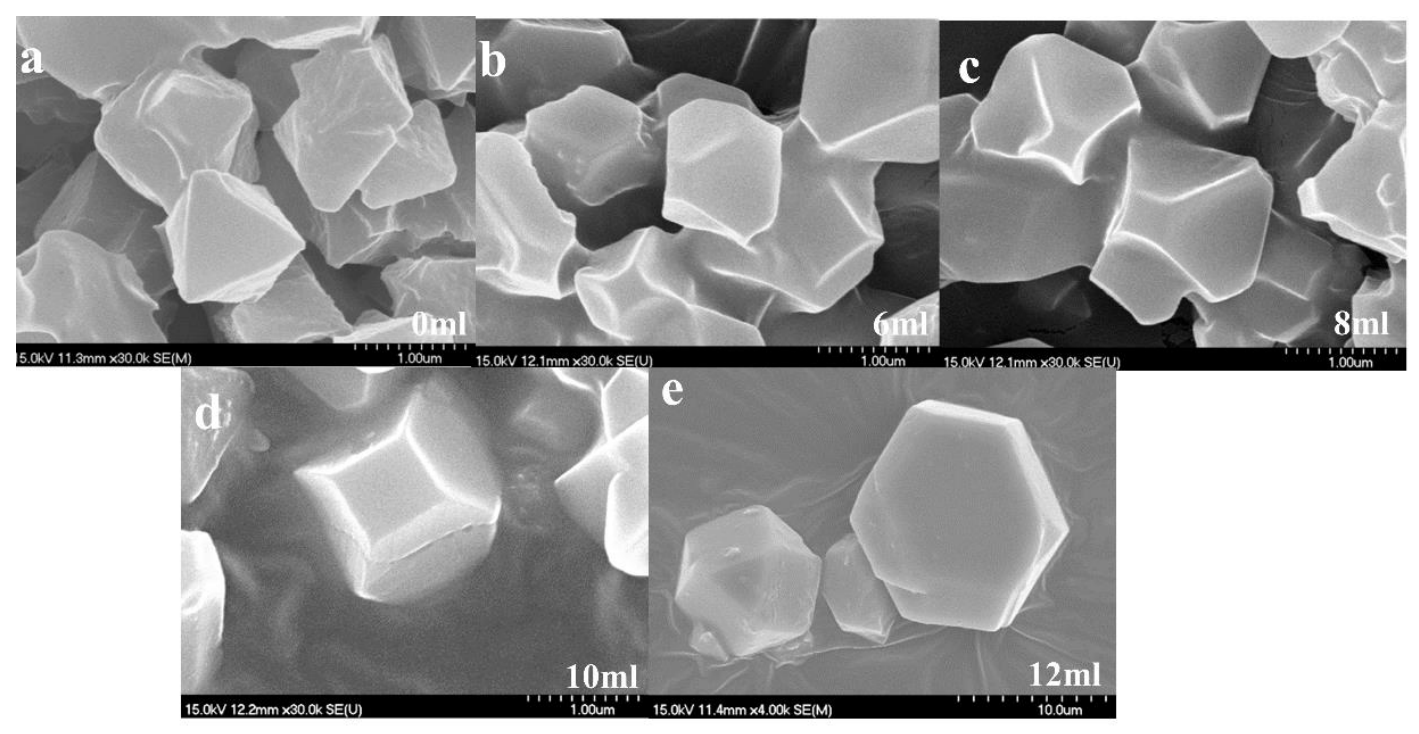

Figure S2. SEM images of PA@HKUST-1 synthesized with different amounts of water. (a) $0 \mathrm{ml}$. (b) $6 \mathrm{ml}$. (c) $8 \mathrm{ml}$. (d) $10 \mathrm{ml}$. (e) $12 \mathrm{ml}$. 


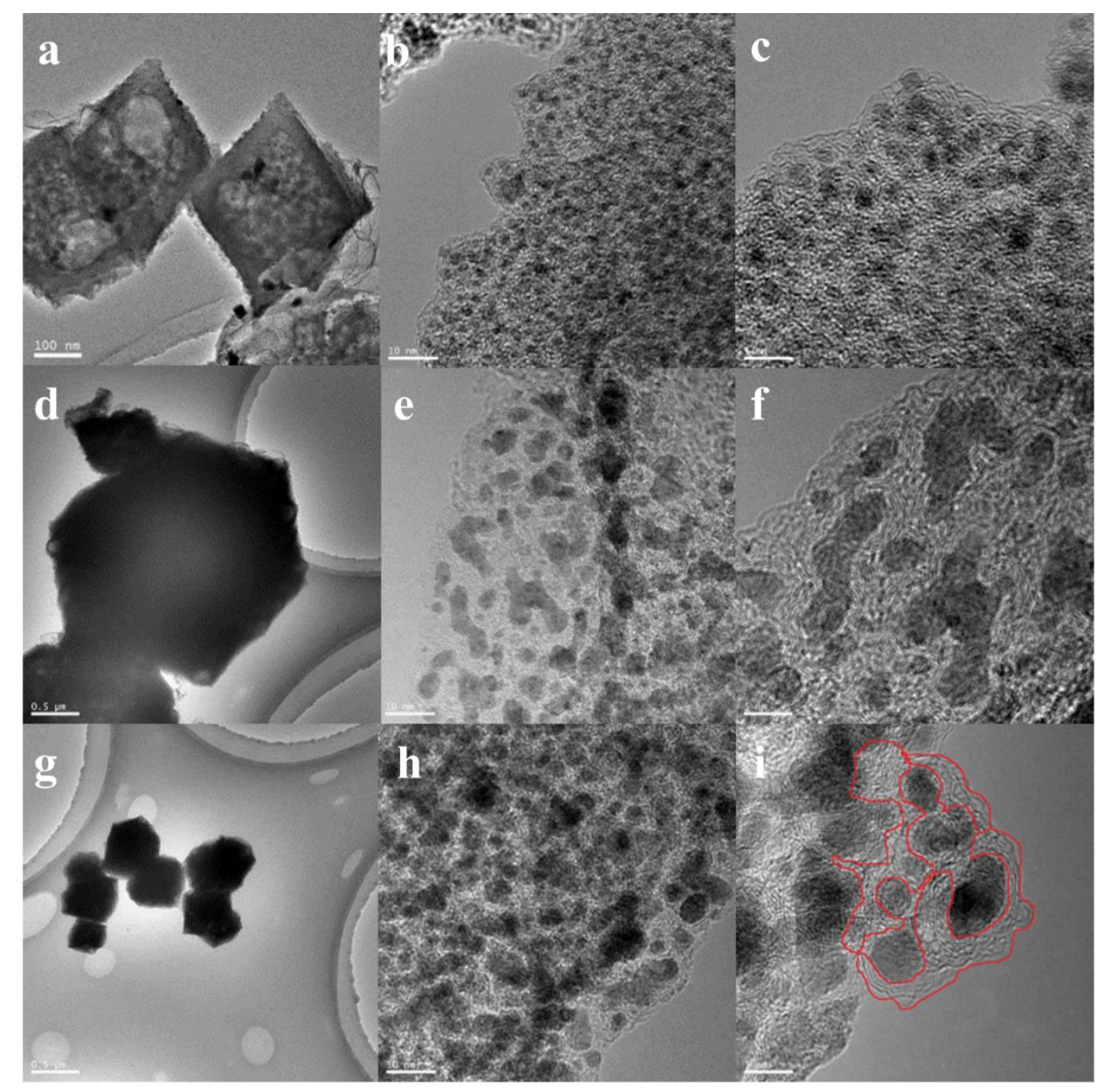

Figure S3. TEM images of $(\mathrm{a}, \mathrm{b}, \mathrm{c}) \mathrm{WO}_{\mathrm{x}} \mathrm{C}_{\mathrm{y}} / \mathrm{C}$ using ethanol as the crystallizing solvent; (d, e, f) $\mathrm{WO}_{\mathrm{x}} \mathrm{C}_{\mathrm{y}} / \mathrm{C}$ using $50 \% \mathrm{v} / \mathrm{v}$ ethanol/water as the crystallizing solvent; $(\mathrm{g}$, $\mathrm{h}, \mathrm{i}) \mathrm{WO}_{\mathrm{x}} \mathrm{C}_{\mathrm{y}} / \mathrm{C}$ using ethanol as the crystallizing solvent and pTA as the end-capped reagent. 


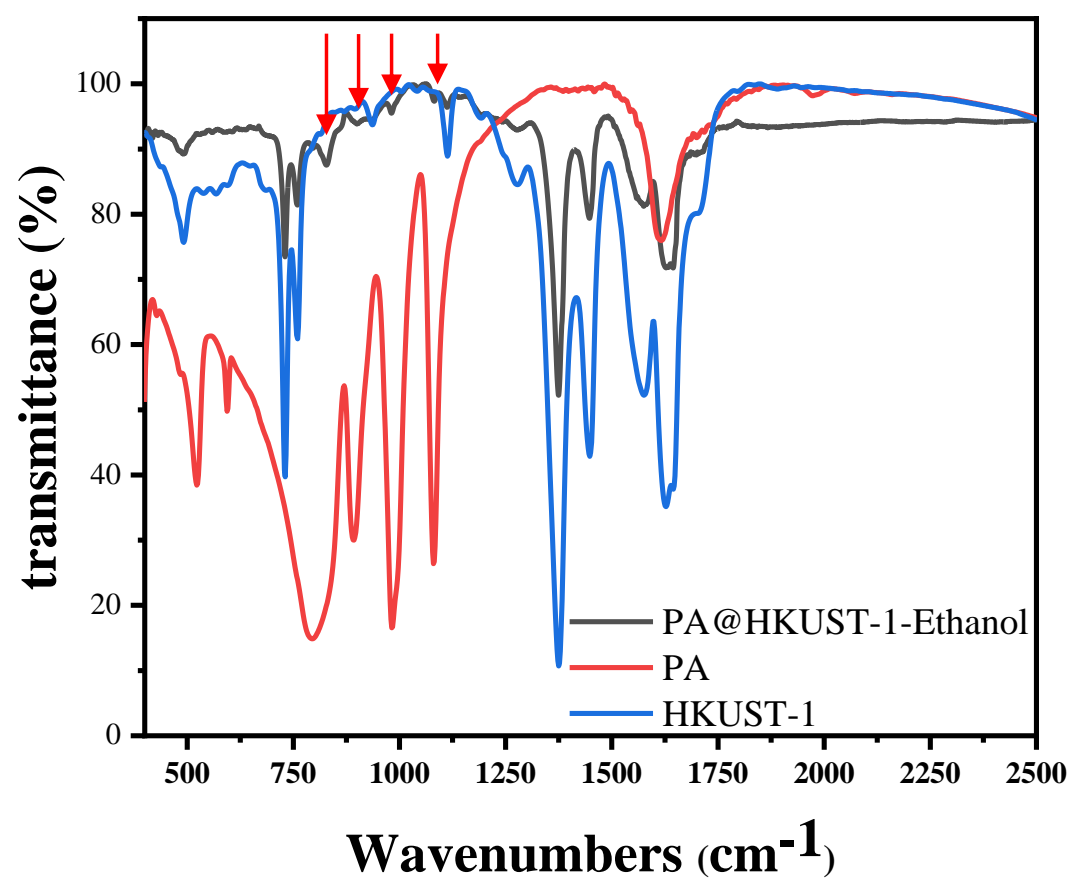

Figure S4. The FTIR spectra of precursor and contrast sample. PA fingerprint peaks are marked by the red arrows. 


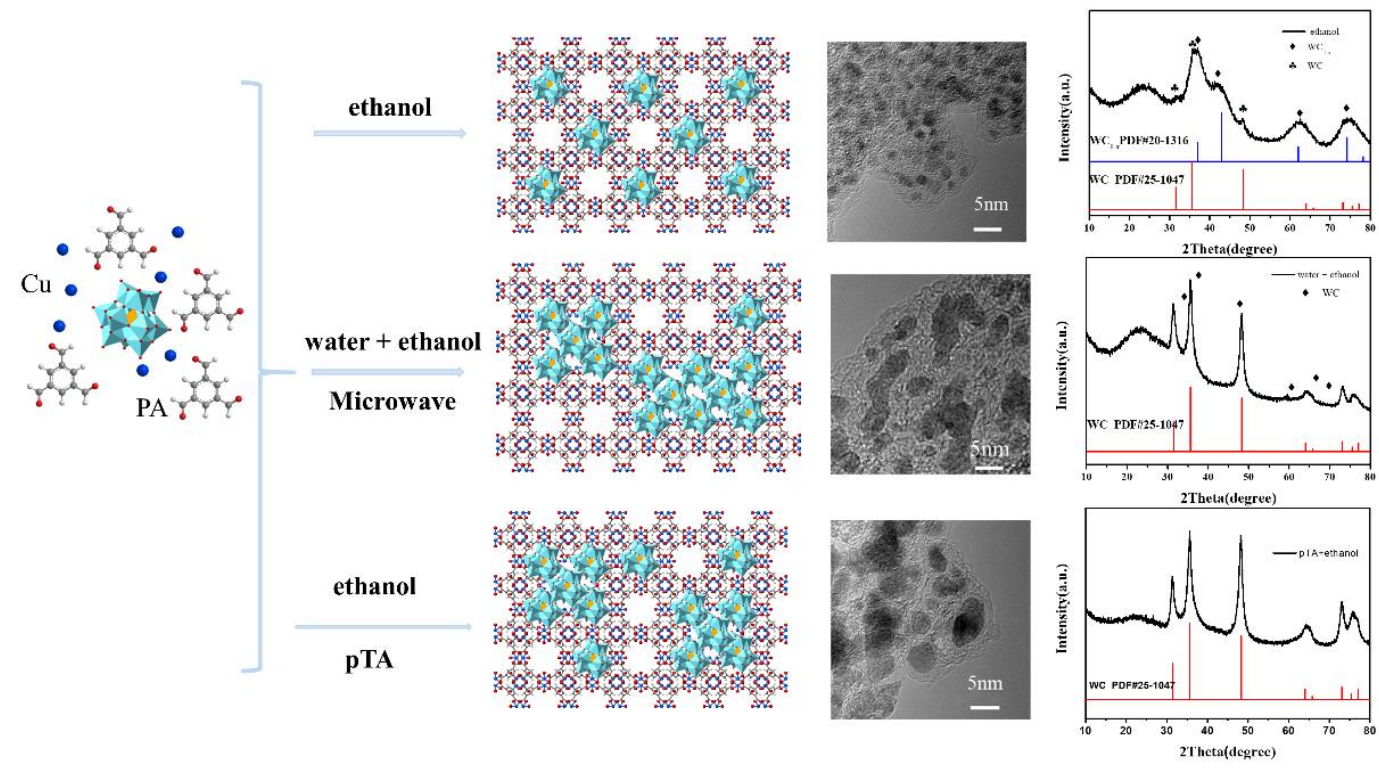

Figure S5. The illustration of the preparation of $\mathrm{WO}_{\mathrm{x}} \mathrm{C}_{\mathrm{y}} / \mathrm{C}-700$. 


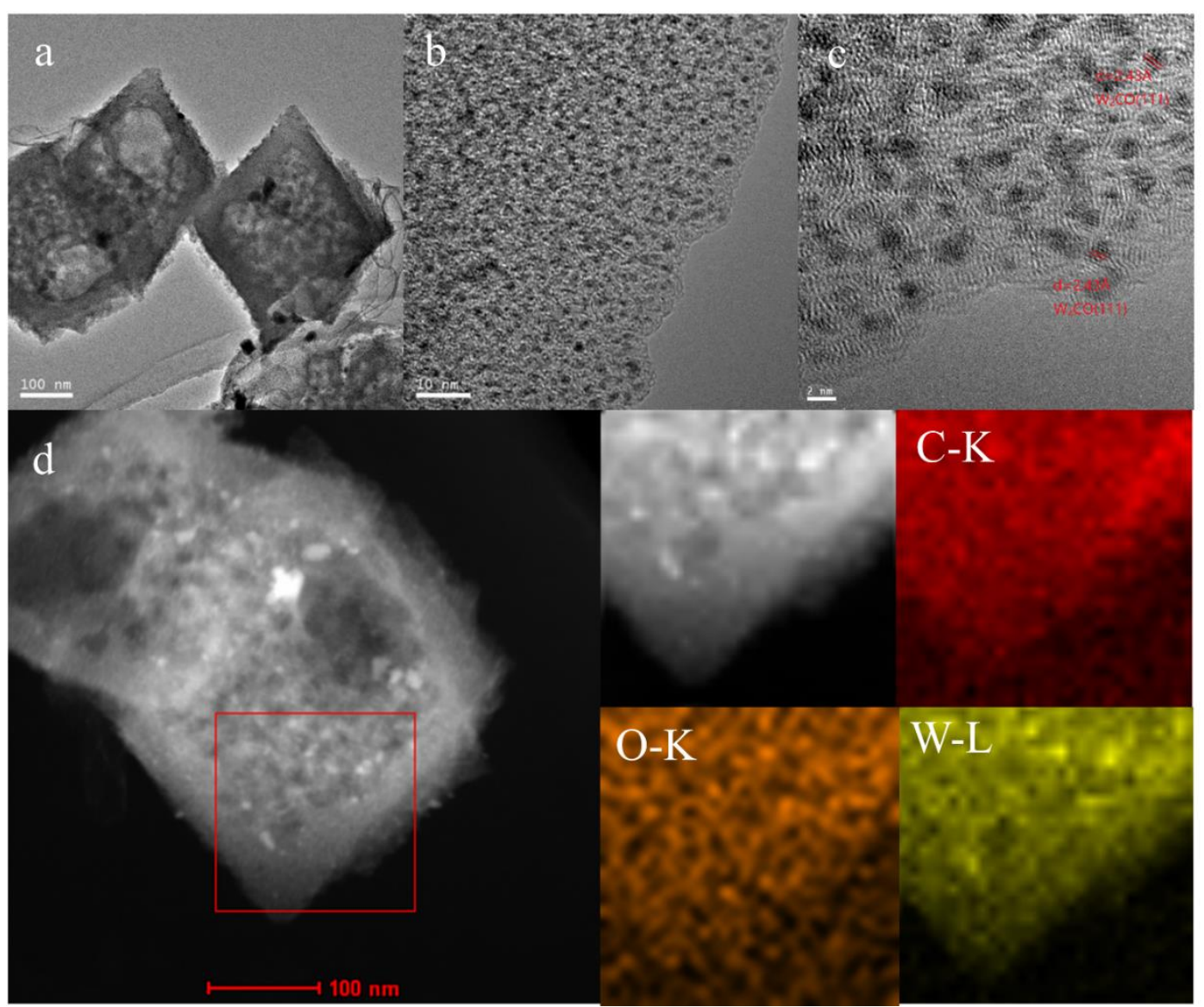

Figure S6. (a, b, c) TEM and HRTEM images of $\mathrm{WO}_{\mathrm{x}} \mathrm{C}_{\mathrm{y}} / \mathrm{C}-700$. (d) Mapping images of $\mathrm{WO}_{\mathrm{x}} \mathrm{C}_{\mathrm{y}} / \mathrm{C}-700$. 

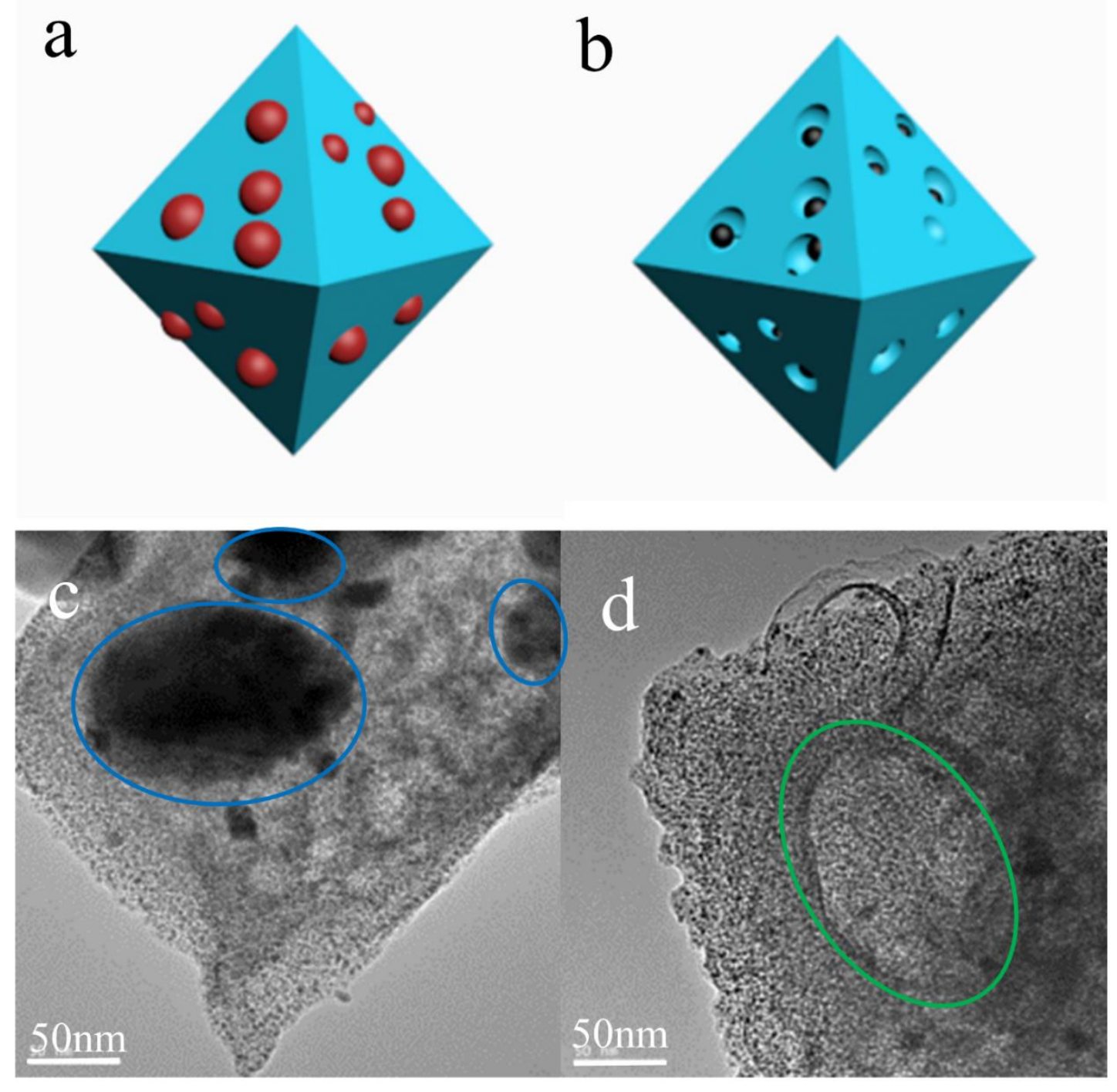

Figure S7. Schematic diagrams of (a) $\mathrm{WO}_{\mathrm{x}} \mathrm{C}_{\mathrm{y}} / \mathrm{C}-\mathrm{Cu}$ and (b) $\mathrm{WO}_{\mathrm{x}} \mathrm{C}_{\mathrm{y}} / \mathrm{C}$ after $\mathrm{Cu}$ particles being washed. TEM images of (c) $\mathrm{WO}_{\mathrm{x}} \mathrm{C}_{\mathrm{y}} / \mathrm{C}-\mathrm{Cu}$ and (d) $\mathrm{WO}_{\mathrm{x}} \mathrm{C}_{\mathrm{y}} / \mathrm{C}$ after $\mathrm{Cu}$ particles being washed. 

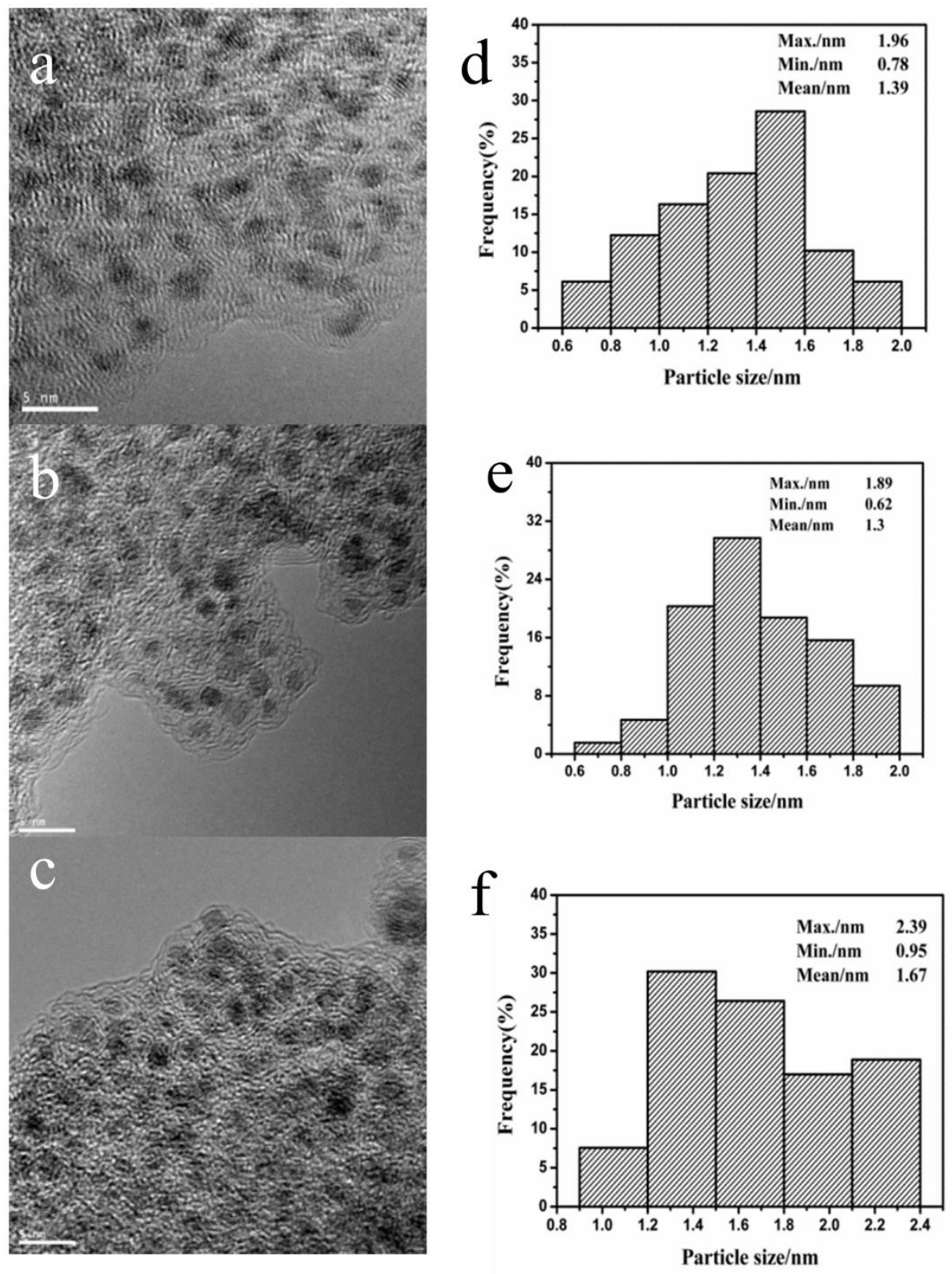

Figure S8. TEM images of (a) $\mathrm{WO}_{\mathrm{x}} \mathrm{C}_{\mathrm{y}} / \mathrm{C}-700$. (b) $\mathrm{WO}_{\mathrm{x}} \mathrm{C}_{\mathrm{y}} / \mathrm{C}-800$ and (c) $\mathrm{WO}_{\mathrm{x}} \mathrm{C}_{\mathrm{y}} / \mathrm{C}-900$. Particle size distributions of (d) $\mathrm{WO}_{\mathrm{x}} \mathrm{C}_{\mathrm{y}} / \mathrm{C}-700$. (e) $\mathrm{WO}_{\mathrm{x}} \mathrm{C}_{\mathrm{y}} / \mathrm{C}-800$ and (f) $\mathrm{WO}_{\mathrm{x}} \mathrm{C}_{\mathrm{y}} / \mathrm{C}-900$. 


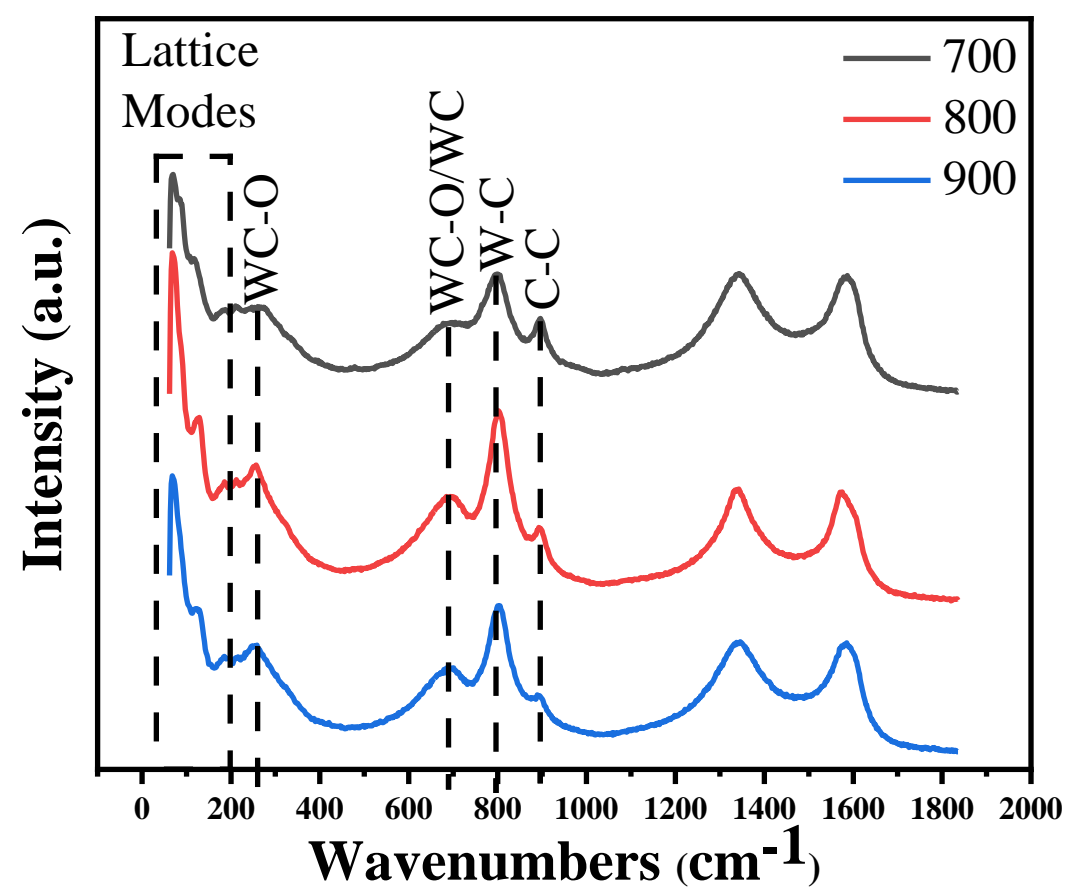

Figure S9. Raman spectra of $\mathrm{WO}_{\mathrm{x}} \mathrm{C}_{\mathrm{y}} / \mathrm{C}-700, \mathrm{WO}_{\mathrm{x}} \mathrm{C}_{\mathrm{y}} / \mathrm{C}-800, \mathrm{WO}_{\mathrm{x}} \mathrm{C}_{\mathrm{y}} / \mathrm{C}-900$. 


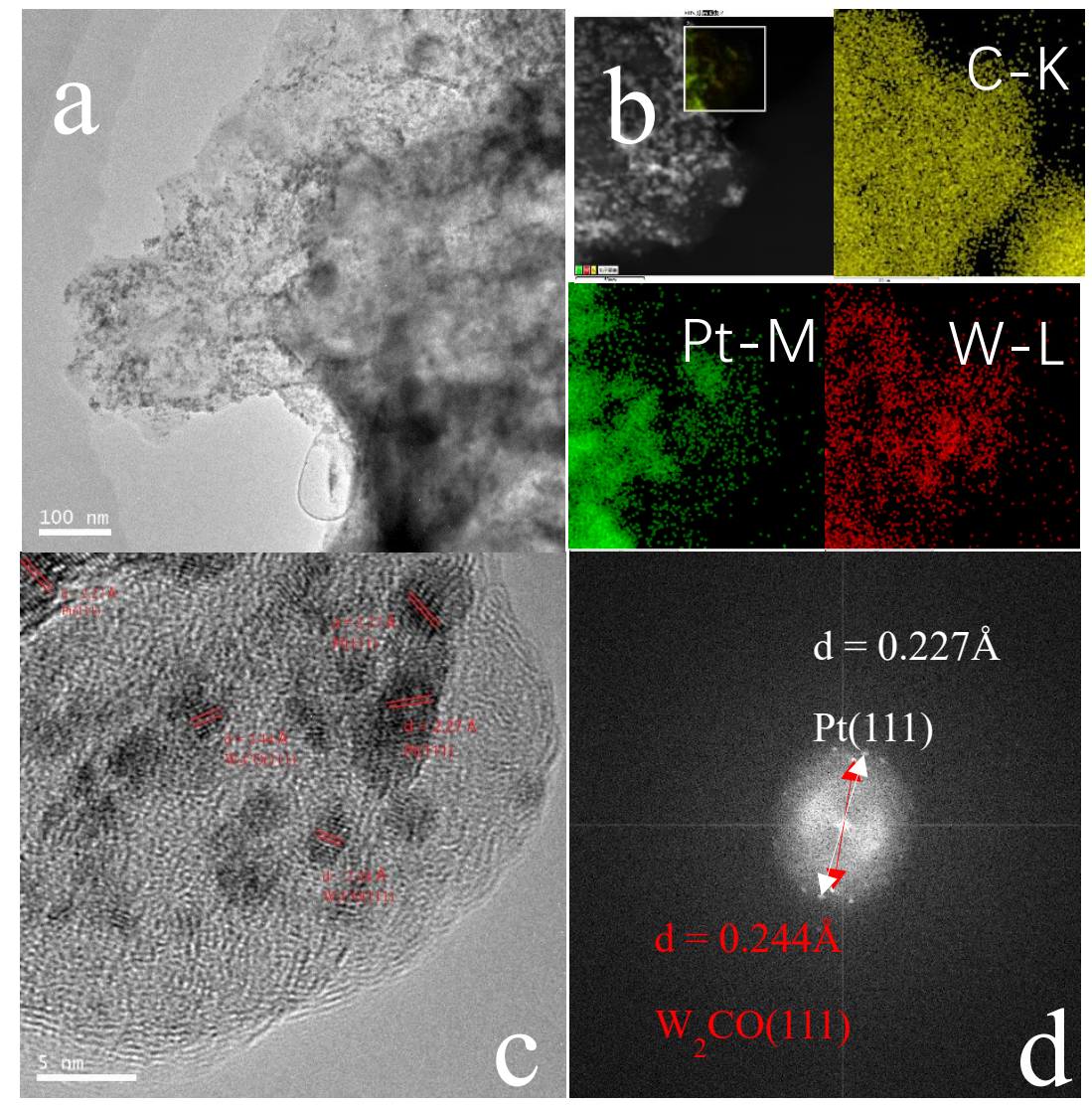

Figure S10. (a, c) TEM and HRTEM images of $\mathrm{Pt} / \mathrm{WO}_{\mathrm{x}} \mathrm{C}_{\mathrm{y}} / \mathrm{C}-700$ after chronoamperometry experiment $\left(0.5 \mathrm{M} \mathrm{H}_{2} \mathrm{SO}_{4}+0.5 \mathrm{M} \mathrm{CH}_{3} \mathrm{OH}\right.$ at $0.65 \mathrm{~V}$ vs SCE for 6000 s). (b) Mapping images with the corresponding EDX analysis of $\mathrm{Pt} / \mathrm{WO}_{\mathrm{x}} \mathrm{C}_{\mathrm{y}} / \mathrm{C}-700$ after chronoamperometry experiment. (d) The FFT pattern of the sample. 

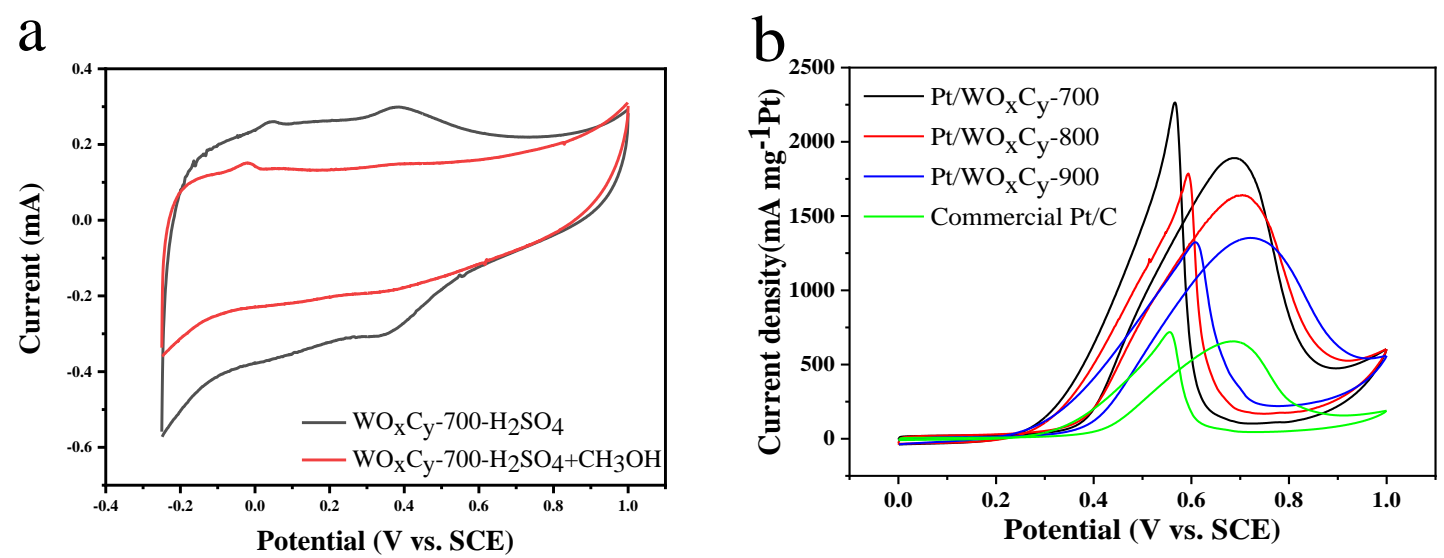

Figure S11. (a)The $\mathrm{CV}$ curves of $\mathrm{WO}_{\mathrm{x}} \mathrm{C}_{\mathrm{y}}-700$ tested in $0.5 \mathrm{M} \mathrm{H}_{2} \mathrm{SO}_{4}$ solution and 0.5

$\mathrm{M} \mathrm{H}_{2} \mathrm{SO}_{4}+0.5 \mathrm{M} \mathrm{CH}_{3} \mathrm{OH}$, respectively. (b) The CV curves of catalysts in $0.5 \mathrm{M}$

$\mathrm{H}_{2} \mathrm{SO}_{4}+0.5 \mathrm{M} \mathrm{CH}_{3} \mathrm{OH}$ solution 

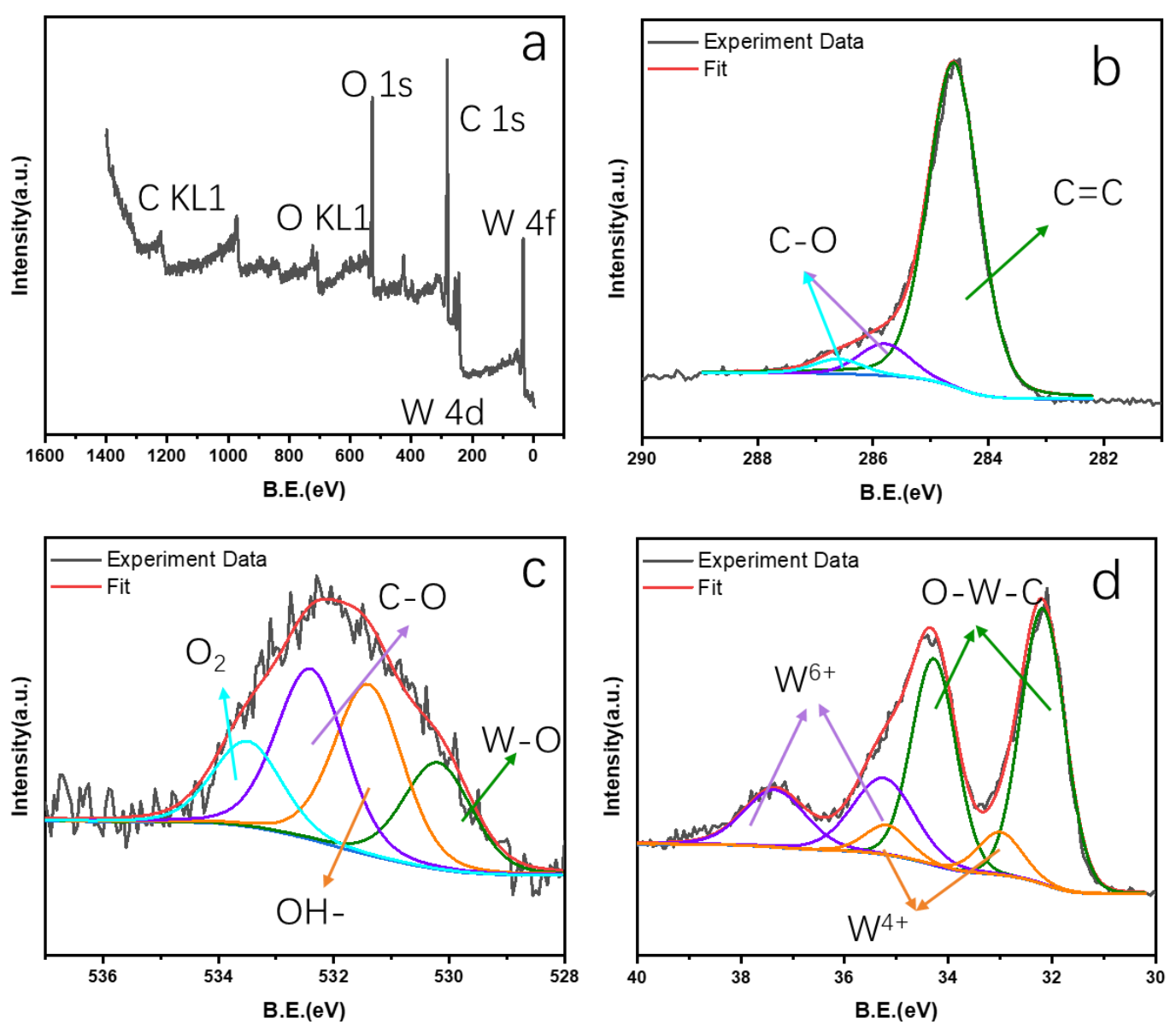

Figure S12. XPS spectra of $\mathrm{WO}_{x} \mathrm{C}_{y} / \mathrm{C}-800$ (a) XPS survey scan in wide region. (b) C 1s, (c) O 1s, (d) W 4f. 

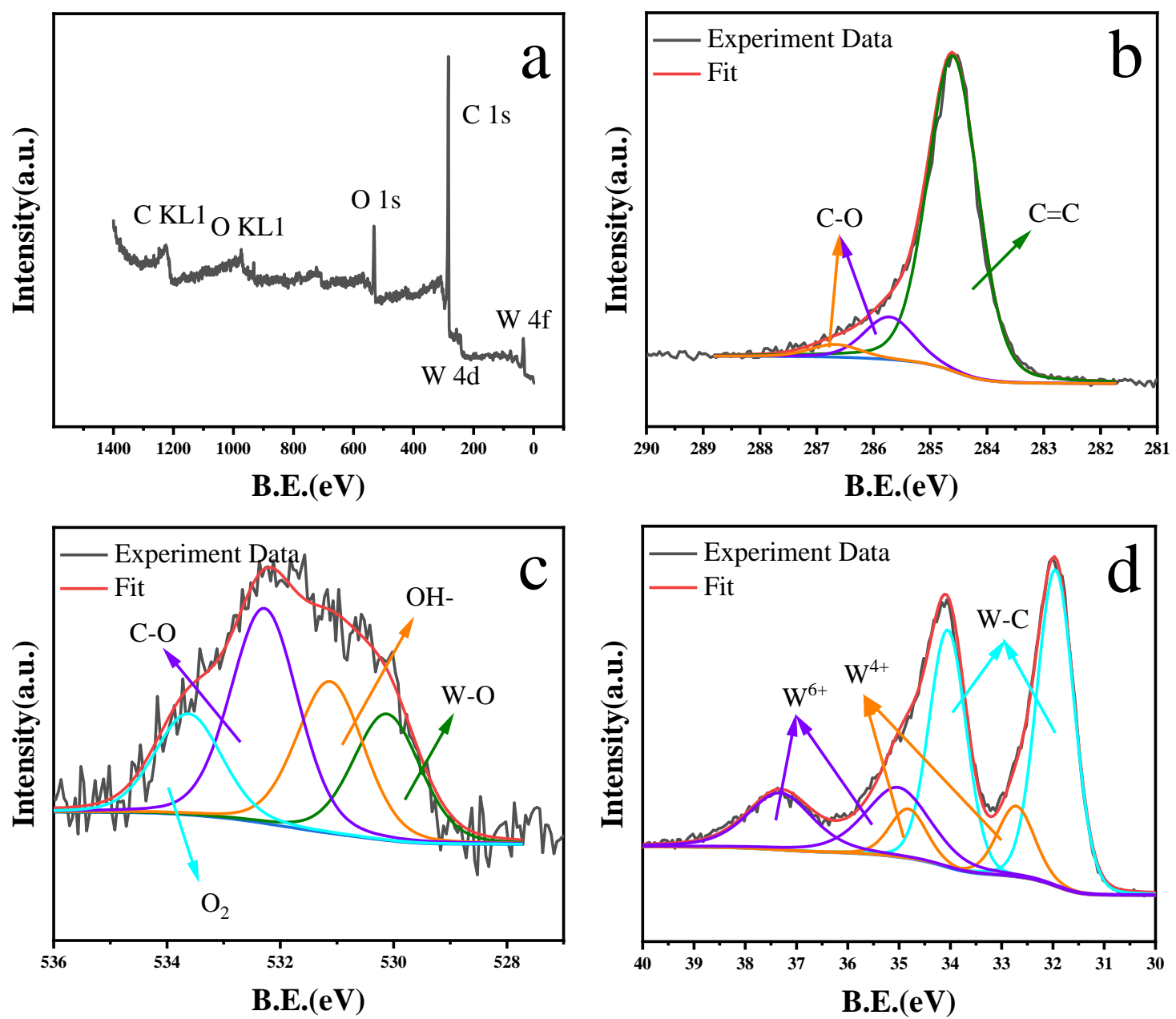

Figure S13. XPS spectra of $\mathrm{WO}_{\mathrm{x}} \mathrm{C}_{\mathrm{y}} / \mathrm{C}-900$ (a) XPS survey scan in wide region. (b) $\mathrm{C}$ 1s, (c) O 1s, (d) W 4f. 
Table S1. The results of morphological control by using different solvent system.

\begin{tabular}{|c|c|c|c|c|c|}
\hline $\begin{array}{l}\text { Water } \\
(\mathrm{mL})\end{array}$ & $\begin{array}{c}\text { Ethanol } \\
(\mathrm{mL})\end{array}$ & Modulator & $\begin{array}{l}\text { Size of } \\
\text { PA@HKUST-1 }\end{array}$ & $\begin{array}{l}\text { morphology of } \\
\text { PA@HKUST-1 }\end{array}$ & Size of $\mathrm{WO}_{x} \mathrm{C}_{\mathrm{y}}(\mathrm{nm})$ \\
\hline 0 & 24 & - & $1 \mu \mathrm{m}$ & & $\sim 1.5 \mathrm{~nm}$ \\
\hline 6 & 18 & water & $1-2 \mu \mathrm{m}$ & & - \\
\hline 8 & 16 & water & $2-3 \mu \mathrm{m}$ & & - \\
\hline 10 & 14 & water & $3-5 \mu \mathrm{m}$ & & - \\
\hline 12 & 12 & water & $5-7 \mu \mathrm{m}$ & & $\sim 3-5 \mathrm{~nm}$ \\
\hline 0 & 24 & pTA & $1 \mu \mathrm{m}$ & & $\sim 5 \mathrm{~nm}$ \\
\hline
\end{tabular}

Table S2. The ECSACO of different sample

\begin{tabular}{ccccc}
\hline Sample & $\mathrm{Pt} / \mathrm{WO}_{\mathrm{x}} \mathrm{C}_{\mathrm{y}}-700$ & $\mathrm{Pt} / \mathrm{WO}_{\mathrm{x}} \mathrm{C}_{\mathrm{y}}-800$ & $\mathrm{Pt} / \mathrm{WO}_{\mathrm{x}} \mathrm{C}_{\mathrm{y}}-900$ & $\mathrm{Pt} / \mathrm{C}$ \\
\hline $\mathrm{ECSA}_{\mathrm{co}}\left(\mathrm{m}^{2} / \mathrm{g}\right)$ & 52.22 & 47.67 & 42.52 & 39.26 \\
\hline
\end{tabular}


Table S3. The XPS W 4f $7 / 2$ semiquantitative results of $\mathrm{WO}_{\mathrm{x}} \mathrm{C}_{\mathrm{y}} / \mathrm{C}-700, \mathrm{WO}_{\mathrm{x}} \mathrm{C}_{\mathrm{y}} / \mathrm{C}-800$, $\mathrm{WO}_{\mathrm{x}} \mathrm{C}_{\mathrm{y}}-900$.

\begin{tabular}{|c|c|c|c|c|}
\hline Sample & Peak Position (eV) & Chemical State & Peak Area & Relative Content (\%) \\
\hline$W_{x} C_{y} / C-700$ & 32.35 & O-W-C & 540 & 46.2 \\
\hline$W_{x} C_{y} / C-700$ & 33.44 & $W^{4+}$ & 40 & 3.4 \\
\hline $\mathrm{WO}_{x} \mathrm{C}_{\mathrm{y}} / \mathrm{C}-700$ & 35.43 & $W^{6+}$ & 590 & 50.4 \\
\hline$W_{x} C_{y} / C-800$ & 32.18 & O-W-C & 1800 & 63.1 \\
\hline$W_{x} C_{y} / C-800$ & 33.00 & $W^{4+}$ & 300 & 10.3 \\
\hline$W_{x} C_{y} / C-800$ & 35.25 & $W^{6+}$ & 750 & 26.3 \\
\hline$W_{x} C_{y} / C-900$ & 31.95 & W-C & 2350 & 60.6 \\
\hline$W_{x} C_{y} / C-900$ & 32.72 & $W^{4+}$ & 550 & 14.2 \\
\hline$W_{x} C_{y} / C-900$ & 35.02 & $W^{6+}$ & 976 & 25.2 \\
\hline
\end{tabular}

Table S4. The total energy of different O-doped WC (001) model.

\begin{tabular}{|c|c|c|c|}
\hline \multirow[t]{2}{*}{ Model Name } & \multirow[t]{2}{*}{ Total Energy $(\mathrm{eV})$} & \multicolumn{2}{|c|}{ Structure drawings } \\
\hline & & Front View & Top View \\
\hline WC $\left(\begin{array}{lll}0 & 0 & 1\end{array}\right)-01$ & -61472.218 & 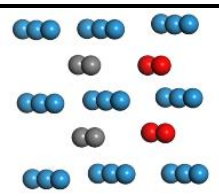 & $0^{\circ} 0^{\circ} 0^{\circ} 0$ \\
\hline WC $\left(\begin{array}{lll}0 & 0 & 1\end{array}\right)-\mathrm{O} 2$ & -61472.28 & 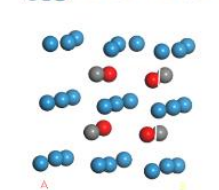 & $\begin{array}{lll}0 & 0 & 0 \\
0 & 0 & 0 \\
0 & 0 & 0\end{array}$ \\
\hline WC (lllll $\left.0 \begin{array}{ll}0 & 1\end{array}\right)-\mathrm{O} 3$ & -61469.639 & $\begin{array}{c}-000000 \\
0000 \\
0000000 \\
0000 \\
0000000\end{array}$ & $\begin{array}{llll} & 0 & 0 & 0 \\
0 & 0 & 0 & 0 \\
0 & 0 & 0\end{array}$ \\
\hline
\end{tabular}

Grey: Carbon, Red: Oxygen, Light blue: Tungsten 
Table S5. The Pt-adhesion energy in different model.

\begin{tabular}{ccc}
\hline Model & Adsorption Site & Eadhesion $(\mathrm{eV})$ \\
\hline & Top & Transform to Fcc Site \\
Bt/WC (001) & Fcc & Transform to Hcp Site \\
& Hcp & -11.71 \\
Top & -12.34 \\
& Bridge & Transform to Hcp Site \\
& Fcc $/ \mathrm{WO}_{\mathbf{x}} \mathrm{C}_{\mathrm{y}}(001)$ & Transform to Fcc Site \\
& Hcp & -12.68 \\
\hline
\end{tabular}

Table S6. The CO-adsorb energy in different model.

\begin{tabular}{|c|c|c|}
\hline Model & Adsorption Site & $\mathrm{E}_{\mathrm{ads}}(\mathrm{eV})$ \\
\hline \multirow{4}{*}{ Pt (111) } & Top & -1.87 \\
\hline & Bridge & -1.90 \\
\hline & Fcc & -1.85 \\
\hline & $\mathrm{Hcp}$ & -1.83 \\
\hline \multirow{4}{*}{$\mathrm{Pt} / \mathrm{WC}(001)$} & Top & -1.60 \\
\hline & Bridge & -1.18 \\
\hline & Fcc & -1.02 \\
\hline & $\mathrm{Hcp}$ & -1.02 \\
\hline \multirow{9}{*}{$\mathrm{Pt} / \mathrm{WO}_{x} \mathrm{C}_{\mathrm{y}}(001)$} & OTop & -1.37 \\
\hline & CTop & -1.32 \\
\hline & CCBridge & Transform to CTop Site \\
\hline & COBridge & Transform to OTop Site \\
\hline & OOBridge & -1.21 \\
\hline & $\mathrm{CCOH}$ сp & Transform to OTop Site \\
\hline & $\mathrm{COOH} c p$ & Transform to OOBridge Site \\
\hline & CCOFcc & Transform to OTop Site \\
\hline & COOFcc & Transform to OTop Site \\
\hline
\end{tabular}




\section{Section II}

\section{ORR performance of $\mathrm{WO}_{2.83} / \mathrm{C}$.}

The oxygen-defect tungsten oxides $\mathrm{WO}_{2.83}$ uniformly distributed on the $3 \mathrm{D}$ carbon matrix were successfully synthesized using the same PA@HKUST-1precursor after annealed under Ar at $700^{\circ} \mathrm{C}$. Figure S14a exhibits the powder XRD pattern of $\mathrm{WO}_{2.83}$ which presents a similar curve to that of $\mathrm{WO}_{2.83}$ (JCPDS NO: 00-036-0103), suggesting $\mathrm{WO}_{2.83}$ which hold plenty of oxygen vacancies can be produced in this process. The oxygen vacancy was triggered in Ar atmosphere where provides the oxygen deficient environment, along with the carbon matrix reducing tungsten oxide at high temperature. Figure $\mathrm{S} 14 \mathrm{~b}$ was the XPS spectra of the $\mathrm{WO}_{2.83} / \mathrm{C}$. The peak at $36.6 \mathrm{eV}$ and $38.75 \mathrm{eV}$ belong to $\mathrm{W}^{6+} \mathrm{W} 4 \mathrm{f}$. The peaks which are much lower, at 35.8 $\mathrm{eV}$ and $37.95 \mathrm{eV}$ are the characteristic $\mathrm{W} 4 \mathrm{f}$ peaks of $\mathrm{W}^{5+}$, which reveals the existence of rich oxygen-defects, agreed with XRD result ${ }^{1-3}$.
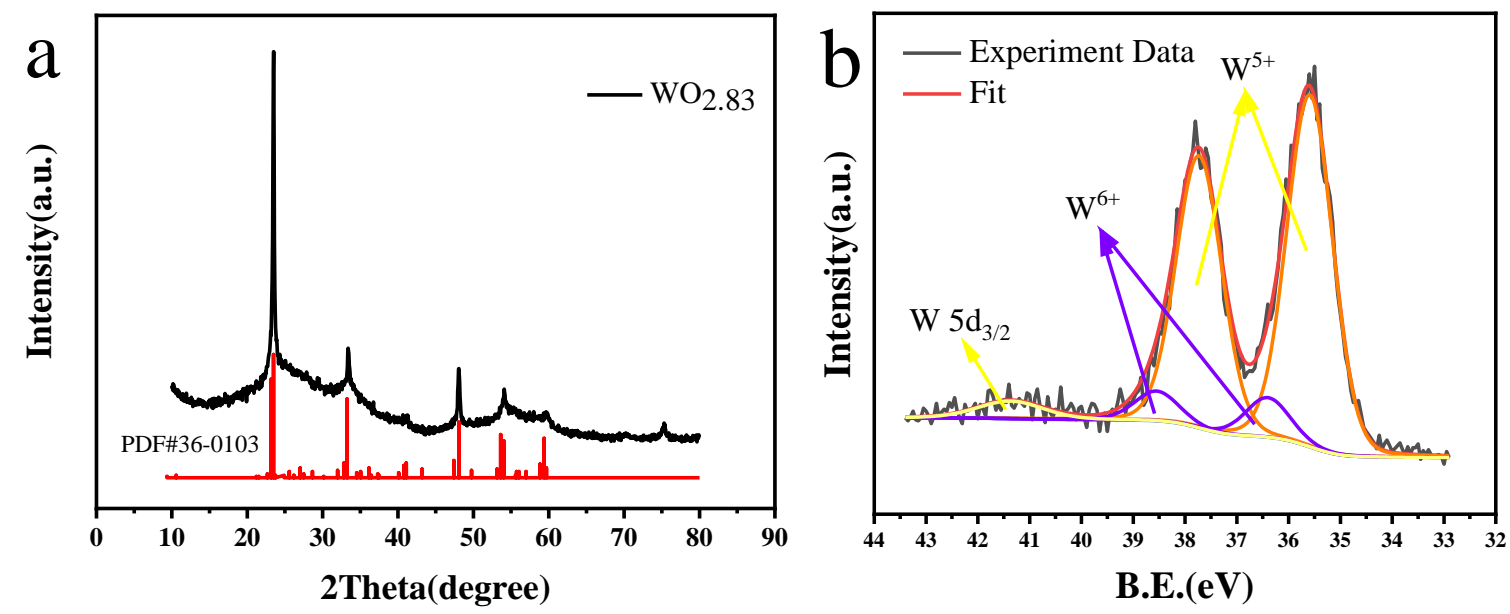

Figure S14. (a) XRD pattern of $\mathrm{WO}_{2.83} / \mathrm{C}$. (b) XPS spectra of $\mathrm{W} 4 \mathrm{f}$ of the $\mathrm{WO}_{2.83} / \mathrm{C}$. 
Morphology and chemical composition of the tungsten oxide samples were investigated by TEM (Figure S15). The morphology and microstructures of the $\mathrm{WO}_{2.83} / \mathrm{C}$ are similar with those of $\mathrm{WO}_{\mathrm{x}} \mathrm{C}_{\mathrm{y}} / \mathrm{C}$. Furthermore, they both kept the initial porous structure and octahedral morphology. The EDS mapping confirmed the uniform distribution of $\mathrm{C}, \mathrm{O}, \mathrm{W}$ in the whole nano-octahedral carbon, respectively.

In order to investigate the catalytic performance of the 3D electrocatalyst in the ORR, rotating disk electrode (RDE) experiments were performed in $\mathrm{O}_{2}$-saturated 0.1 $\mathrm{M} \cdot \mathrm{KOH}$ solutions with a scan rate of $5 \mathrm{mV} \mathrm{s}^{-1}$ and a rotating speed of $1600 \mathrm{rpm}$ at

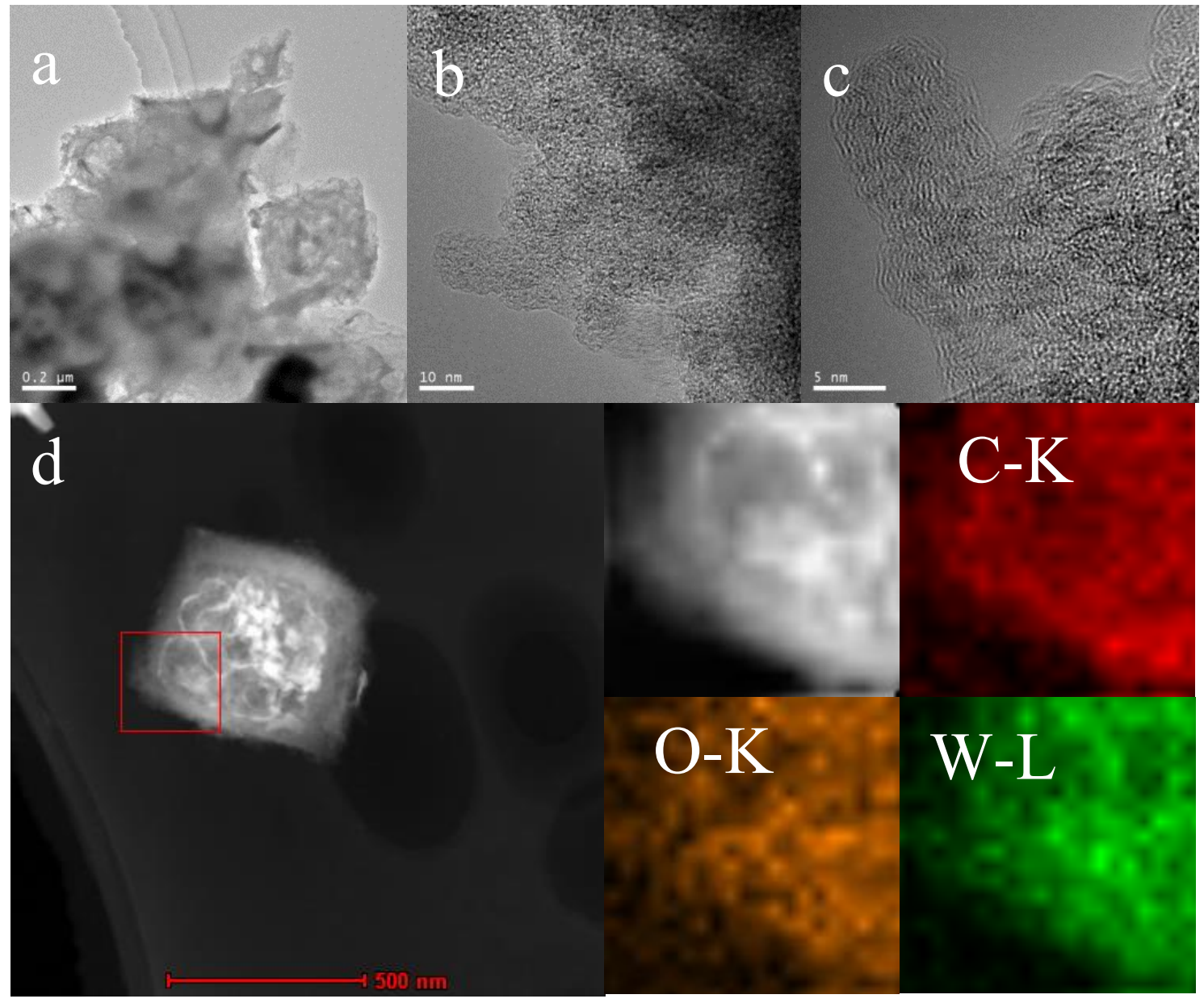

Figure S15. (a, b, c) TEM and HRTEM images of $\mathrm{WO}_{2.83}$ /C. (d) Mapping images of $\mathrm{WO}_{2.83} / \mathrm{C}$. 
room temperature (Figure S16c). The polarization curves of all carbon supported catalysts exhibited two distinguishable potential regions, corresponding to well-defined diffusion limiting currents $(0.2 \sim 0.7 \mathrm{~V})$ followed by a mixed kinetic-diffusion control region $(0.7 \sim 0.95 \mathrm{~V})$. The onset potential $(0.90 \mathrm{~V})$ of $\mathrm{WO}_{2.83} / \mathrm{C}$ is close to that of benchmarked $\mathrm{Pt} / \mathrm{C}$ (onset potential: $0.95 \mathrm{~V}$ ). The Koutechy-Levich (K-L) plots (Figure S16b) of the $\mathrm{WO}_{2.83} / \mathrm{C}$ obtained from the LSV curves at different rotating rates from 1600 to $100 \mathrm{rpm}$ (Figure S16a) according to the $\mathrm{K}-\mathrm{L}$ equation yield an electron transferred number (n) of approximately 3.96, indicating its superior ORR catalytic activity through a four-electron pathway. All these results indicate that $\mathrm{WO}_{2.83} / \mathrm{C}$ is the effective catalyst for ORR and the possible reasons can be explained by the existence of abundant oxygen defects on the material surface which can greatly accelerate the breakage of the $\mathrm{O}-\mathrm{O}$ bond. 

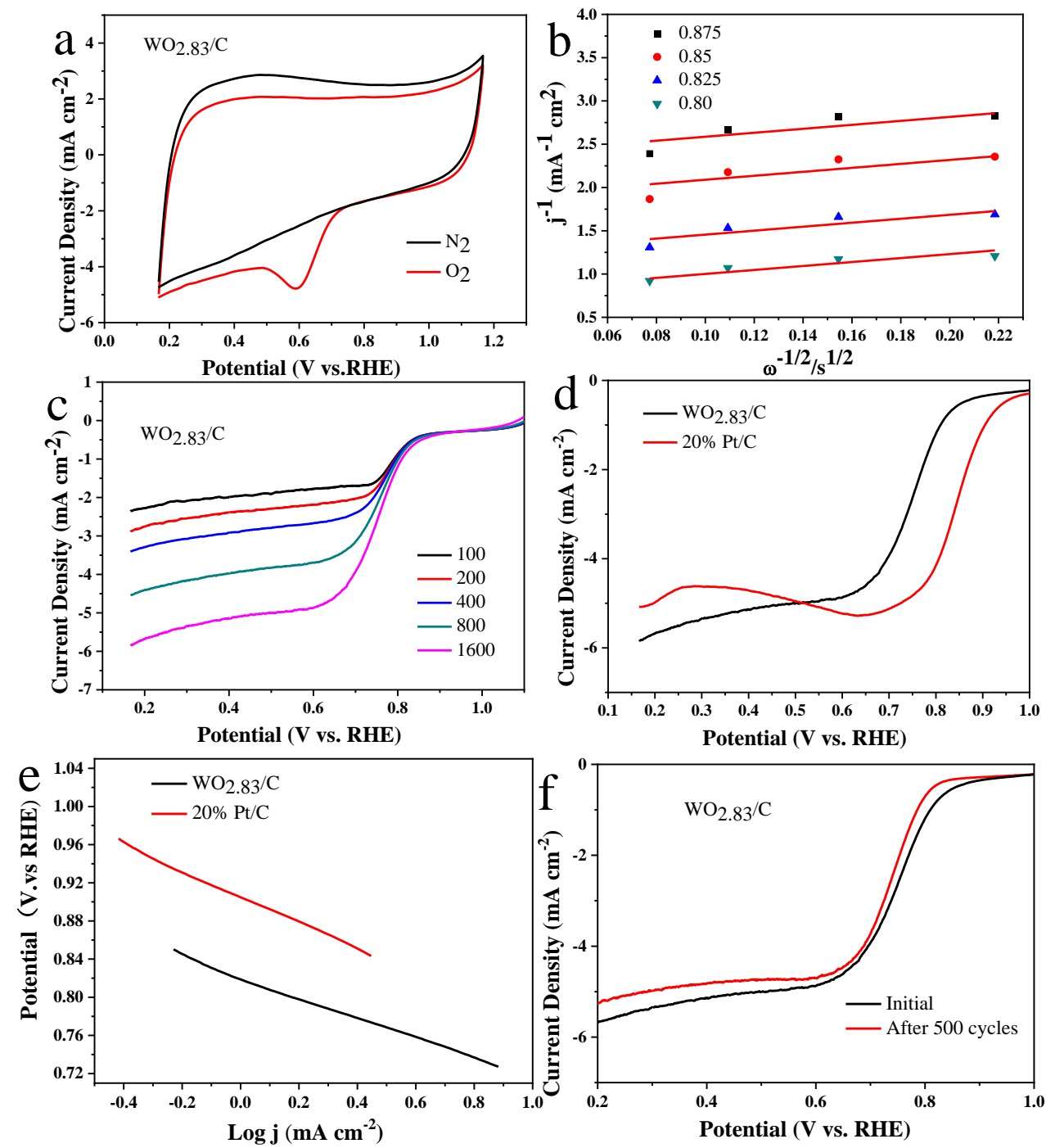

Figure S16. (a) $\mathrm{CVs}$ in $0.1 \mathrm{M} \mathrm{KOH}$ of $\mathrm{WO}_{2.83} / \mathrm{C}$. (b) The corresponding $\mathrm{K}-\mathrm{L}$ plot of $\mathrm{WO}_{2.83} / \mathrm{C}$. (c) Polarization curves during oxygen reduction for $\mathrm{WO}_{2.83} / \mathrm{C}$ catalysts in $\mathrm{O}_{2}$ saturated $0.1 \mathrm{M} \mathrm{KOH}$ at the rotation rates of 100, 200, 400, 800 and $1600 \mathrm{rpm}$ and at a scan rate of $5 \mathrm{mV} \mathrm{s}^{-1}$ for. (d) $\mathrm{LSVs}_{\mathrm{S}}$ of $\mathrm{WO}_{2.83} / \mathrm{C}$ and $\mathrm{Pt} / \mathrm{C}$ in $0.1 \mathrm{M} \mathrm{KOH}$ at $1600 \mathrm{rpm}$. (e) Tafel plots from the $\mathrm{WO}_{2.83} / \mathrm{C}$ and $\mathrm{Pt} / \mathrm{C}$. (f) comparison of polarization curves of the $\mathrm{WO}_{2.83} / \mathrm{C}$ before and after the 500 cycles chronoamperometry test at a potential range of $0.4-1.2 \mathrm{~V}$ (vs RHE) in the $\mathrm{O}_{2}$-saturated $0.1 \mathrm{M} \mathrm{KOH}$ and with rotating speed of $1600 \mathrm{rpm}$ 


\section{Experimental Section/Methods}

The preparation of $\mathrm{WO}_{2.83} / \mathrm{C}$. The precursor was heated to $700^{\circ} \mathrm{C}$ under $\mathrm{Ar}$ flow with a ramp rate of $5^{\circ} \mathrm{C} \mathrm{min}^{-1}$ and kept at each temperature for $3 \mathrm{~h}$ and then cooled down naturally under $\mathrm{N}_{2}$ flow. The as-prepared oxygen-defect tungsten oxide sample was denoted as $\mathrm{WO}_{2.83}-\mathrm{Cu}$. The copper particles were removed by dispersing the sample in $\mathrm{FeCl}_{3}$ aqueous solution for $12 \mathrm{~h}$ at ambient condition. The resulted porous $\mathrm{WO}_{2.83}$ nano-octahedrons were collected by centrifugation, repeatedly washed with deionized water and ethanol, then dried at $60^{\circ} \mathrm{C}$ overnight. The resultants were marked as $\mathrm{WO}_{2.83}$.

\section{Electrochemical measurements.}

$3 \mathrm{mg}$ of catalyst was dispersed in a suspension containing $180 \mu \mathrm{L}$ isopropyl alcohol and $20 \mu \mathrm{L}$ Nafion ( $5 \mathrm{wt} \%$, Du Pont Corp. USA) under ultrasonic stirring for $30 \mathrm{~min}$. Then the catalyst ink was deposited on the surface of GC-electrode. A Pt foil $\left(2 \mathrm{~cm}^{2}\right)$ and a $\mathrm{Hg} / \mathrm{HgO}$ electrode were used as the counter and reference electrode, respectively. All potentials referred to in this paper are converted to the $\mathrm{pH}$-independent reversible hydrogen electrode (RHE) to compare with the value in the literature according to equation (1).

$\mathrm{E}_{\mathrm{vs} . \mathrm{RHE}}=\mathrm{E}_{\mathrm{vs} . \mathrm{Hg} / \mathrm{HgO}}+0.059 * \mathrm{pH}+\mathrm{E}_{\mathrm{Hg} / \mathrm{HgO}}$

\section{Electrocatalyst evaluation in ORR:}

All the electrodes were pretreated using $\mathrm{CV}$ cycling from -0.7 to $0.3 \mathrm{~V}$ (vs $\mathrm{Hg} / \mathrm{HgO}$ )

in $0.1 \mathrm{M} \mathrm{KOH}$ solution at a sweep rate of $50 \mathrm{mV} \mathrm{s}^{-1}$ for 20 cycles to activate electrodes. The dissolved oxygen was removed before the ORR activity tests in $\mathrm{N}_{2}$ 
saturated $0.1 \mathrm{M} \mathrm{KOH}$ solution until a stable cyclic voltammogram was recorded. Then, the electrolyte was saturated with oxygen by bubbling $\mathrm{O}_{2}$ for 30 min prior to the ORR activity tests. A flow of $\mathrm{O}_{2}$ was maintained over the electrolyte to ensure $\mathrm{O}_{2}$ saturation during the recording of CV. Linear-sweep voltammetry (LSV) measurements were conducted under $\mathrm{O}_{2}$-saturated circumstance by sweeping the potential negatively from $0.3 \mathrm{~V}$ to $-0.7 \mathrm{~V}(\mathrm{vs} \mathrm{Hg} / \mathrm{HgO})$ at a scan rate of $5 \mathrm{mV} \mathrm{s}^{-1}$ with varying rotating speed from 1600 to $100 \mathrm{rpm}$. Koutecky-Levich plots $\left(\mathrm{i}^{-1}\right.$ vs $\left.\omega^{-1 / 2}\right)$ were analyzed at various electrode potentials. The number of electrons transferred (n) was calculated on the basis of the Koutecky-Levich equation where $\mathrm{J}$ is the experimentally obtained current; $\mathrm{J}_{\mathrm{L}}$ refers to the measured diffusion-limited current; and $\mathrm{J}_{\mathrm{k}}$ is the mass-transport free kinetic current. $\mathrm{n}$ is the number of electrons transferred; F refers to the Faraday's constant (96485 $\left.\mathrm{C} \mathrm{mol}^{-1}\right)$; A corresponds to the area of the electrode $\left(0.0706 \mathrm{~cm}^{2}\right)$; D represents the diffusion coefficient of $\mathrm{O}_{2}$ in $0.1 \mathrm{M} \mathrm{KOH}$ solution (1.9 $\left.\times 10^{-5} \mathrm{~cm}^{2} \mathrm{~s}^{-1}\right)$; v reflects the kinematic viscosity of the electrolyte $\left(0.01 \mathrm{~cm}^{2} \mathrm{~s}^{-1}\right)$; $\omega$ is the angular frequency.

\section{References}

(1) Zheng, X.; Dong, X.; Zhang, S.; Yang, J., Defect-induced ferromagnetism in $\mathrm{W}_{18} \mathrm{O}_{49}$ nanowires. J. Alloys Compd. 2020, 818, 152894.

(2) Büyükköse, S., Highly selective and sensitive $\mathrm{WO}_{3}$ nanoflakes based ammonia sensor. Mater. Sci. Semicond. Process. 2020, 110, 104969.

(3) Castillo, C.; Cabello, G.; Chornik, B.; Huentupil, Y.; Buono-Core, G. E., Characterization of photochemically grown $\mathrm{Pd}$ loaded $\mathrm{WO}_{3}$ thin films and its evaluation as ammonia gas sensor. J. Alloys Compd. 2020, 825, 154166. 